\title{
La elección del derecho aplicable en el derecho internacional privado en Colombia
}

\author{
The Choice of the Applicable Law in International Private \\ Law in Colombia \\ A eleição do direito aplicável no direito internacional privado \\ na Colômbia
}

\author{
MARÍA JULIA OCHOA JiMÉNEZ \\ JONATHAN ZAPATA FLÓREZ ${ }^{* * *}$ \\ PaOla Carrillo Gamboa ${ }^{\star \star \star \star}$
}

FECHA DE RECEPCIÓN: 5 DE JUNIO DE 2018. FECHA DE APROBACIÓN: 29 DE JUNIO DE 2018

DoI: http://dx.doi.org/10.12804/revistas.urosario.edu.co/sociojuridicos/a.6784

Para citar este artículo: Ochoa Jiménez, M. J., Zapata Flórez, J. \& Carrillo Gamboa, P. (2019). La elección del derecho aplicable en el derecho internacional privado en Colombia. Estudios Socio-Jurídicos, 21(1), 91-120. Doi: http://dx.doi. org/10.12804/revistas.urosario.edu.co/sociojuridicos/a.6784

* Artículo resultado del proyecto de investigación "La norma de conflicto en Colombia: un examen de flexibilidad". Investigadora principal: María Julia Ochoa Jiménez. Coinvestigadores: Jonathan Zapata Flórez y Paola Carrillo Gamboa. Proyecto adscrito a las líneas de investigación "Derecho internacional privado", del grupo de investigación Estudios Internacionales: Derecho, Economía, Política y Relaciones Internacionales, y "Contratación privada contemporánea", del grupo de investigación Saber, Poder y Derecho. Financiado por la Facultad de Derecho y Ciencias Políticas de la Universidad de Antioquia.

** María Julia Ochoa Jiménez. Abogada (Universidad de los Andes, Venezuela) con maestría y doctorado en Derecho Internacional (Georg-August-Universität Göttingen, Alemania) y formación posdoctoral (Rheinische Friedrich-Wilhelms-Universität Bonn, Alemania). Profesora de la Facultad de Derecho y Ciencias Políticas de la Universidad de Antioquia. ORCID: http://orcid. org/0000-0002-3701-9018. Correo electrónico: julia.ochoa@udea.edu.co / mariajulia85@yahoo. com

*** Jonathan Zapata Flórez. Politólogo (Universidad Nacional de Colombia) y abogado con especialización en Derecho Procesal (Universidad de Antioquia) y especialización en Derecho Comercial (Universidad Autónoma Latinoamericana), estudiante de maestría en Derecho (Universidad Pontificia Bolivariana). Profesor de la Facultad de Derecho y Ciencias Políticas de la Universidad de Antioquia. ORCID: http://orcid.org/0000-0002-3954-4684. Correo electrónico: jonathan.zapataf@udea.edu.co

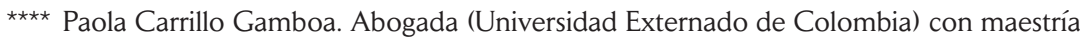
en Contratos y Responsabilidad de los Profesionales (Universidad de Toulouse Capitole, Francia) y maestría en Derecho Internacional y Derecho Europeo (Universidad de Toulouse Capitole, Francia). Profesora de la Facultad de Derecho y Ciencias Políticas de la Universidad de Antioquia. Correo electrónico: paola.carrillo@udea.edu.co 


\section{RESUMEN}

Hoy en día, en Colombia, como en otros países, es cada vez más común encontrar situaciones jurídicas privadas internacionales, es decir, situaciones a las cuales son aplicables normas del derecho internacional privado. El presente artículo presenta los resultados de una investigación cualitativa a través de la cual se identificaron y evaluaron normas de conflicto de leyes del ordenamiento jurídico colombiano, considerando algunas formas de flexibilización presentes en codificaciones no directamente aplicables en Colombia. Teniendo como centro de atención la posibilidad para las partes de elegir la ley aplicable a una situación jurídica privada internacional, se halló que en Colombia las normas de conflicto de leyes existentes no responden de manera adecuada a las exigencias de las realidades que emergen de hechos y negocios jurídicos contemporáneos, por lo que se exhorta a realizar una revisión legal que brinde mayor seguridad jurídica.

Palabras clave: Colombia, derecho internacional privado, conflicto de leyes, autonomía de la voluntad, flexibilización.

\section{ABSTRACT}

Currently, in Colombia, as in other countries, it is increasingly common to find international private legal situations, that is, situations to which the rules of the international private law are applicable. This article presents the results of a qualitative research through which conflict-of-laws rules of the Colombian legal system were identified and evaluated, considering some forms of flexibilization present in codifications not directly applicable in Colombia. With a focus on the possibility for the parties to choose the law applicable to an international private legal situation, it was found that in Colombia conflict-of-laws rules do not adequately respond to what is required by realities emerging from facts and businesses, so it is encouraged to carry out reforms in order to offer more legal certainty.

Keywords: Colombia, international private law, conflict of laws, party autonomy, flexibility.

\section{RESUMO}

Atualmente, na Colômbia, como em outros países, é cada vez mais comum encontrar situações jurídicas privadas internacionais, é dizer, situações às quais são aplicáveis normas do direito internacional privado. O presente artigo apresenta os resultados de uma pesquisa qualitativa através da qual se identificaram e avaliaram normas de conflito de leis do ordenamento jurídico colombiano, considerando algumas formas de flexibilização presentes em codificações não diretamente aplicáveis na Colômbia. Tendo como centro de atenção a possibilidade para as partes de eleger a lei aplicável a uma situação jurídica privada internacional, achou-se que na Colômbia as normas de conflito de leis existentes não respondem adequadamente às exigências das realidades que emergem de factos e negócios jurídicos contemporâneos, pelo que se exorta a realizar uma revisão legal que brinde maior segurança jurídica.

Palavras-chave: Colômbia, direito internacional privado, conflito de leis, autonomia da vontade, flexibilização. 


\section{Introducción}

Podríamos pensar en el régimen de alimentos de dos hermanos colombianos domiciliados en Uruguay, de madre colombiana y padre estadounidense, o en la sucesión de una persona que poseía bienes en diferentes países de América, pero sin domicilio en ninguno de ellos. También podríamos imaginar un contrato de compraventa celebrado en Portugal sobre un bien producido en España, importado por una sociedad panameña y cuyo destinatario final se encuentra domiciliado en Colombia. Estas situaciones representan relaciones jurídicas privadas con elementos de extranjería o, dicho de otro modo, relaciones jurídicas privadas internacionales (Calvo Caravaca \& Carrascosa González, 2015, p. 2; Álvarez Londoño \& Galán Barrera, 2001, p. 41). En este tipo de situaciones se encuentran en latencia conflictos de jurisdicción y conflictos de leyes; los primeros se refieren a la necesidad de determinar los tribunales competentes para conocer y decidir sobre una situación jurídica privada internacional y los segundos aluden a la necesidad de establecer el ordenamiento jurídico que le es aplicable. El derecho internacional privado estudia este tipo de conflictos y, con base en ello, busca establecer las normas que rigen las relaciones jurídicas privadas internacionales (Monroy Cabra, 2016, p. 19). Estas normas son denominadas normas de conflicto de jurisdicción, en el primer caso, y normas de conflicto de leyes, en el segundo ${ }^{1}$. El presente artículo se enmarca en el estudio de este último tipo de normas de conflicto.

Para identificar el derecho aplicable a las situaciones jurídicas privadas internacionales, las normas de conflicto de leyes utilizan los denominados factores de conexión ${ }^{2}$ que son aspectos fácticos como, por ejemplo, la nacionalidad, el domicilio, la residencia, el lugar donde se encuentra el

1 Las normas de conflicto de leyes también pueden ser denominadas "normas de colisión". Otra forma de describir la función de estas es la que trae Kegel (1982, p. 165), para quien las normas de colisión son normas de conexión, puesto que vinculan un caso a determinadas normas jurídicas.

2 En la doctrina colombiana pueden encontrarse diversas denominaciones para esta figura, por ejemplo, "elemento vinculante" (Mantilla Rey, 1982), "puntos de conexión" (Álvarez Londoño E Galán Barrera, 2001), "punto de conexión o vinculación" (Marín Fuentes, 2014) o "punto de contacto" (García Matamoros et al., 2016). 
bien, el lugar donde se realiza el acto jurídico, el lugar donde se cumplirán las obligaciones o la elección hecha por las partes. De esta forma, cuando una norma de conflicto de leyes, para gobernar determinada situación, declara como aplicable el derecho del domicilio de una de las partes, el derecho del lugar donde se encuentra el bien o el derecho elegido por las partes, se utiliza como factor de conexión, respectivamente, el domicilio, la situación del bien o la autonomía de la voluntad (Monroy Cabra, 2016, pp. 84-86).

Al haberse desarrollado en el marco del proyecto de investigación titulado "La norma de conflicto en Colombia: un examen de flexibilidad", el presente artículo contribuye al objetivo general de dicho proyecto que ha consistido en evaluar las normas de conflicto de leyes del ordenamiento jurídico colombiano a partir de mecanismos de flexibilización que pudieran ser identificados en codificaciones existentes en otros ordenamientos jurídicos. El desarrollo de la investigación ha conducido a identificar diferentes puntos problemáticos; uno de los que merece mayor atención es el que tiene que ver con la ausencia de regulación en Colombia en torno a la autonomía de las partes para la elección de la ley aplicable a una situación jurídica privada internacional. Es así como el artículo tiene como punto de pivote la situación en el país en relación con dicha autonomía. De manera que, si bien el ámbito contractual es donde la autonomía de las partes adquiere su mayor expresión, el fin del artículo no consiste, propiamente, en tratar de manera exhaustiva la regulación de la contratación internacional en Colombia.

Este artículo se propone, por una parte, presentar, de manera general, la situación actual en el país en cuanto a la autonomía de las partes para la elección de la ley aplicable dada la inexistencia de un reconocimiento legal de dicha autonomía ${ }^{3}$. Por otra parte, expone brevemente la situación en algunos países donde el principio de autonomía de las partes para la elección de la ley aplicable sí se encuentra reconocido legalmente, tanto en el campo contractual como en otros campos, lo que permite reflexionar sobre el estado actual de dicho asunto en el ámbito 
nacional. Y, puesto que se parte de la idea de que sería conveniente que Colombia contara con una regulación sobre este tema, en aras de ofrecer una mayor seguridad jurídica, con este artículo se busca, finalmente, aportar algunas consideraciones que podrían ser tomadas en cuenta a la hora de formular dicha regulación.

Dichas consideraciones se exponen desde dos perspectivas. La primera de ellas toma en cuenta la importancia creciente de la flexibilización de las normas de conflicto, lo que ha sido resaltada por algunos autores como Basedow (2017, pp. 58 y s.). Para ello, nos basamos, principalmente, en las formas de flexibilización identificadas por Symeonides (2011, 2014), partiendo de que la flexibilización es un atributo de las normas de conflicto en tanto normas codificadas. La segunda perspectiva se refiere a la necesidad de tomar en cuenta la internacionalidad de las situaciones y la desigualdad de poder que puede subyacer en ellas.

\section{Aproximación preliminar a la autonomía de la voluntad en el derecho internacional privado}

La autonomía de la voluntad ha sido tradicionalmente reconocida en diversos órdenes jurídicos nacionales e internacionales, sobre todo en materia contractual. En este contexto se distingue entre la autonomía de la voluntad en sentido material, que permite a las partes determinar el contenido del contrato ${ }^{4}$, y la autonomía de la voluntad en sentido conflictual, que les otorga la facultad de escoger el derecho aplicable al mismo (Calderón Marenco, 2017; Leible, 2011, p. 215; Rodríguez, 2011, p. 119). Para el derecho internacional privado es relevante, de manera particular, el segundo de los sentidos mencionados.

La idea de que los sujetos envueltos en una situación jurídica privada internacional sean libres de escoger el derecho que regulará dicha

4 Larenz (1956, p. 64) indica que la autonomía de la voluntad es una facultad dada a los individuos para celebrar negocios jurídicos y con ellos crear los efectos jurídicos deseados, dentro de los límites legales. Soto (2005, pp. 18-19) observa que la autonomía de la voluntad se expresa en dos libertades: la libertad de contratar, es decir, decidir si contratar o no, y decidir con quién hacerlo; y la libertad de configuración interna del contrato que implica la facultad para determinar autónomamente el contenido del contrato. 
situación no es nueva en la doctrina del derecho internacional privado. En paralelo al desarrollo de la escuela estatutaria que tuvo lugar a partir del siglo XIII, existía la costumbre de la professio iuris, que consistía, básicamente, en que las personas llevadas a juicio debían establecer la ley por la cual el asunto debía ser decidido. Resulta claro que esta figura sea entendida como un antecedente histórico del principio de la autonomía de la voluntad en materia de conflicto de leyes (Guerra Iñiguez, 1997, p. 49). No obstante, en el siglo XVI Charles Dumoulin desarrolla, a partir de su revisión de las ideas estatutarias italianas (Cock Arango, 1952, p. 45), el concepto de la autonomía de la voluntad (Mantilla Rey, 1982, p. 18). Dumoulin sostuvo que para conocer la ley aplicable a los contratos era determinante conocer la voluntad de los contratantes, idea que extendió a las situaciones referidas a los bienes de los cónyuges en tanto régimen convencional tácito (Basedow, 2017, p. 228; Guerra Iñiguez, 1997, p. 54).

El mayor aporte, influyente hasta nuestros días, ha sido, sin embargo, el de Friedrich Karl von Savigny, quien planteó sus ideas al respecto a mediados del siglo XIX. Para Savigny era necesario que en cada relación jurídica se estableciera el derecho más conforme con la naturaleza propia y esencial de esa relación (Cock Arango, 1952, p. 52; Guerra Iñiguez, 1997, p. 75). Dentro de la teoría de Savigny, la determinación de dicho derecho exigía tomar en cuenta situaciones de hecho que remiten a un lugar en el espacio donde la relación jurídica es creada, concretada o produce sus efectos (Mantilla Rey, 1982, p. 30; Ruiz Díaz, 2013, pp. 254, 266; Schurig, 2014, p. 6; Symeonides, 2016, p. 51). Así, la escogencia del derecho implica para este autor, ante todo, la escogencia del lugar (Junker, 2017, p. 95). En este sentido, en materia contractual, si las partes no realizan la determinación del derecho aplicable al contrato de manera expresa, prevalecerá, según Savigny, la ley del lugar de ejecución del contrato. Y como las partes pueden escoger el lugar donde el contrato será ejecutado, también en este último caso las partes escogen -de manera indirecta o mediata- el derecho aplicable al contrato (Junker, 2017, pp. 54, 95). 


\section{Sinopsis de la situación actual en Colombia: desarrollo doctrinario y jurisprudencial}

En Colombia no se ha reconocido legalmente el principio de autonomía de las partes para la elección de la ley aplicable. La resistencia al reconocimiento expreso de la autonomía de la voluntad en materia de conflicto de leyes podría tener su origen en inquietudes justificadas, como las que tienen que ver con las desigualdades que pueden subyacer entre las partes envueltas en la situación jurídica, o su desconocimiento de los diversos órdenes jurídicos. Sin embargo, puede ser también reflejo de una tradición territorialista.

En este sentido, los conflictos de leyes en materia contractual han sido resueltos en el derecho internacional privado colombiano mediante la aplicación de la ley del lugar de la ejecución o del cumplimiento, si el contrato ha de ser ejecutado o cumplido en territorio colombiano. Es así como el Artículo 869 del Código de Comercio establece: "La ejecución de los contratos celebrados en el exterior que deban cumplirse en el país, se regirá por la ley colombiana" 5 .

No obstante, la doctrina ha seguido a Savigny al interpretar dicho artículo del Código de Comercio para llegar a una interpretación extensiva según la cual el mismo -más allá de incluir el principio lex loci solutionis, que ordena la aplicación de ley del lugar del cumplimiento de las obligaciones contractuales (Zuleta Londoño, 2010, p. 29)- permite que las partes fijen el lugar de cumplimiento, facultándolas así para convenir sobre el derecho aplicable al contrato (Monroy Cabra, 2016, pp. 361-362). Zapata (2016, pp. 199-201) resalta que la norma citada hace referencia a los contratos mercantiles en general, sin importar su naturaleza u objeto, y subraya que dicho artículo se limita a establecer una regla frente a la ejecución del contrato internacional, dejando por fuera ámbitos como la celebración, la validez, la nulidad o la interpretación, a los cuales son

5 En relación con los contratos internacionales estatales, la regla que establece el Artículo 13 de la Ley 80 de 1999 es que los mismos deben ser regidos por la ley del lugar de la celebración o, si deben ejecutarse en Colombia, por la ley del lugar de la ejecución. Este artículo deja espacio a la autonomía de la voluntad de las partes para la escogencia de la ley que regulará al contrato, en la medida en que establece que "[...] los contratos que se celebren en Colombia y deban ejecutarse o cumplirse en el extranjero, podrán someterse a la ley extranjera". 
aplicables otras normas de conflicto. Tanto Monroy Cabra (2016) como Zapata (2016) proponen, entonces, que en Colombia el pacto sobre la ley aplicable a los contratos internacionales, surgido al amparo del principio de la autonomía de la voluntad, ha de ser considerado válido ya que es máxima expresión de la libertad contractual.

Por otra parte, el primer párrafo del Artículo 20 del Código Civil contiene la regla lex rei sitae, según la cual las situaciones privadas internacionales referidas a derechos reales se regulan por la ley del lugar de la ubicación de los bienes ${ }^{6}$. Este artículo prevé, así mismo, la ley aplicable a los efectos que deban surtir en Colombia los contratos celebrados en el exterior que recaigan sobre bienes ubicados en el país. Un sector de la doctrina ha interpretado que este artículo consagra el estatuto real y el contractual al establecer la ley aplicable a los bienes situados en Colombia y los efectos en el país de contratos celebrados en el exterior (cfr. Zapata, 2016, pp. 190-191). Otro sector de la doctrina ha interpretado que el Artículo 20 del Código Civil regula solamente el estatuto real, de manera que la aplicación de la ley colombiana debería limitarse a los bienes situados en el país donde el Estado tenga derechos o interés. Las demás relaciones jurídicas contractuales de naturaleza internacional serían, así, susceptibles de solución a través de las correspondientes reglas y principios del derecho internacional privado en esta materia. Zapata (2016, pp. 194-195) apoya esta solución al proponer una interpretación textual del artículo que establece que dicha norma se aplica a "bienes en cuya propiedad tenga interés o derecho la nación". Así, a los contratos sobre bienes que no encajen en ese supuesto no les es aplicable esa regla y lo

6 Código Civil de Colombia, Artículo 20: "Los bienes situados en los territorios, y aquellos que se encuentren en los Estados, en cuya propiedad tenga interés o derecho la Nación, están sujetos a las disposiciones de este Código, aun cuando sus dueños sean extranjeros y residan fuera de Colombia.

Esta disposición se entenderá sin perjuicio de las estipulaciones contenidas en los contratos celebrados válidamente en país extraño.

Pero los efectos de dichos contratos, para cumplirse en algún territorio, o en los casos que afecten a los derechos e intereses de la Nación, se arreglarán a este código y demás leyes civiles de la unión".

Es de anotar que el Tratado de Montevideo de 1889 sobre Derecho Civil Internacional (Ley aprobatoria 33 de 1992) contiene normas respecto de los contratos que versan sobre derechos reales: artículos 26, 34, 35 y 52 al 55. Sin embargo, la aplicación de este tratado alcanza solamente a los Estados que hacen parte de él, como resalta Orejudo (2013). En cuanto a las garantías mobiliarias, ver el Artículo 83 de la Ley 1676 de 2013, sobre acceso al crédito y garantías mobiliarias que no incluye la autonomía de la voluntad de las partes. 
mismo sucede si el bien se encuentra ubicado fuera de Colombia y la nación no tiene interés o derecho sobre ellos.

En general, al referirse a las normas de conflicto en el ámbito de la contratación privada, Zuleta Londoño (2010, p. 29) ha sostenido que Colombia tiene un sistema errático y destaca la falta de claridad del Código Civil en cuanto a las reglas de ejecución de las obligaciones contractuales con elementos de extranjería?.

Los artículos del Código de Comercio y del Código Civil que han sido mencionados incorporan un sistema unilateral, de carácter rígido. Tomando en cuenta esto, recientemente se ha insistido en que el principio de territorialidad debería ser matizado ya que, de lo contrario, el ordenamiento jurídico estará rezagado frente a las relaciones jurídicas contemporáneas (Zapata, 2016, pp. 194-199). Esta idea, no obstante, no es nueva en la doctrina colombiana. Hace cinco décadas, Caicedo Castilla (1967, p. 241) justificaba su oposición a la territorialidad absoluta de la ley presente en el ordenamiento colombiano aduciendo, entre otras razones, que la misma "se apoya en el concepto de la soberanía territorial absoluta, que impide la aplicación dentro del territorio del Estado, de las leyes extranjeras" (Caicedo Castilla, 1967, p. 242), con base en lo que respaldaba, ya en ese entonces, la necesidad de reforma de la normativa colombiana en esta materia.

Ahora bien, hoy en día, se aprecia una paulatina aceptación de la validez del pacto de ley aplicable en el ámbito judicial. En efecto, la Corte Suprema de Justicia, en el marco de una acción de tutela contra providencia judicial $^{8}$, ha afirmado que en Colombia, a pesar de no ser

7 Este autor excluye, a este respecto, las reglas sobre capacidad pues el Artículo 19 del Código Civil trae una regulación relativamente clara frente a la capacidad de los colombianos residentes y domiciliados en el extranjero cuando sus actos deban ejecutarse en Colombia, pues permanecen sujetos a la ley colombiana. En cuanto a esto hay que decir que esta claridad no es tal en relación con la capacidad de los extranjeros. Véase, por ejemplo, que el Artículo $1^{\circ}$ del Tratado de Montevideo de Derecho Civil Internacional (Ley aprobatoria 33 de 1992) somete la capacidad a las normas del lugar del domicilio. Sobre la incorporación del Tratado de Montevideo de Derecho Civil Internacional y, con ella, la inclusión de la ley del domicilio dentro del ordenamiento jurídico colombiano, ver: Samtleben (1983).

8 Corte Suprema de Justicia. Exp. T-1100122030002002-0109-01. Sala de Casación Civil. 18 de abril de 2002. M. P.: José Fernando Ramírez Gómez. En esta sentencia se decide sobre el rechazo a la admisión de una demanda en la que el juez argumentó falta de competencia territorial, pues las partes del contrato eligieron la ley del Estado de Alabama, Estados Unidos, para regir e interpretar su relación contractual. 
permitido a las partes elegir la jurisdicción competente, sí se admite el pacto sobre el derecho sustancial aplicable ${ }^{9}$. La misma Corte ha aceptado incluso la posibilidad de que las partes pacten como ley del contrato los Principios Unidroit sobre los Contratos Comerciales Internacionales ${ }^{10}$.

Por otra parte, la Corte Constitucional, al referirse al Artículo 6 de la Convención de las Naciones Unidas sobre los Contratos de Compraventa Internacional de Mercaderías, adoptada en Viena el 11 de abril de 1980 (Ley aprobatoria 518 de 1999), ${ }_{11}^{1}$ enfatizaba que:

La Convención no desconoce la autonomía de la voluntad privada, en la medida en que aquella no obstaculiza el derecho a la libertad que estas tienen para contratar de acuerdo [...] En tal virtud, es permitido que las partes que celebren el respectivo contrato puedan excluir, total o parcialmente, la aplicación de sus disposiciones, en forma tácita o expresa de conformidad con el Artículo 6 del Instrumento internacional que se analiza ${ }^{12}$.

Con base en ello se podría sostener que, en dicho artículo, existe un reconocimiento de la validez del pacto de ley aplicable pues, como afirma Zapata (2016, p. 207), dicha norma supone la prerrogativa de descartar la ley interna al imponerse sobre el Artículo 869 del Código de Comercio.

Por otra parte, se ha de mencionar una sentencia de la Corte Suprema de Justicia del 24 de junio de $2016^{13}$. El asunto tratado en ella gira en torno a un contrato de agencia mercantil entre una empresa colombiana y otra estadounidense. Las partes acordaron regir su contrato de acuerdo con la ley del estado de Texas, Estados Unidos, y pactaron una cláusula

9 Argumentación sostenida por el Tribunal Superior de Bogotá. Sentencia 24200142901. Sala Civil. 30 de abril de 2002.

10 Corte Suprema de Justicia. Exp. 11001-3103-040-2006-00537-01. Sala de Casación Civil. 21 de febrero de 2012. M. P.: William Namén Vargas.

11 Convención de las Naciones Unidas sobre los Contratos de Compraventa Internacional de Mercaderías, Artículo 6: "Las partes podrán excluir la aplicación de la presente Convención o, sin perjuicio de lo dispuesto en el Artículo 12, establecer excepciones a cualquiera de sus disposiciones o modificar sus efectos".

12 Corte Constitucional. Sentencia C-529/00. 10 de mayo de 2000. M. P.: Antonio Barrera Carbonell.

13 Corte Suprema de Justicia. Sentencia SC8453-2016. Sala de Casación Civil. 24 de junio de 2016. M. P.: Ariel Salazar Ramírez. 
compromisoria conforme a la cual el tribunal arbitral tendría sede en la ciudad de Houston, siendo aplicables las reglas de la Cámara de Comercio Internacional ${ }^{14}$. Dado que el caso gira en torno a un contrato de agencia, la sentencia se refiere al Artículo 1328 del Código de Comer$\mathrm{cio}^{15}$ que ha sido interpretado de diversas maneras en la doctrina y en la jurisprudencia. Estas interpretaciones son relevantes para comprender la situación en Colombia en cuanto a la libertad de las partes para escoger la ley aplicable a una situación jurídica internacional.

En relación con el Artículo 1328 del Código de Comercio ha existido una postura según la cual el mismo es de carácter obligatorio y, por consiguiente, no admite pacto que conduzca a la aplicación de la ley extranjera. Es así como las partes no estarían facultadas para ejercer la autonomía de la voluntad conflictual para elegir el derecho aplicable. Esta posición se puede encontrar en Zuleta Londoño (2010, p. 29) ${ }^{16}$.

Ciertamente, existe la posibilidad de considerar imperativa la aplicación de una norma de conflicto. Al respecto se ha afirmado en España, por ejemplo, que el carácter imperativo de estas normas se desprende de lo estipulado por el Artículo 12, numeral 6, del Código Civil español que establece que: "Los Tribunales y autoridades aplicarán de oficio las normas de conflicto del derecho español". De allí que se afirme que, en ese país, es claro que el juez no puede apartarse de lo dispuesto en las normas de conflicto (Calvo Caravaca \& Carrascosa González, 2015, p. 391). En Francia, mediante desarrollo jurisprudencial, el carácter imperativo o facultativo de la norma de conflicto ha variado en función de

14 El problema central que se plantea es el rechazo del reconocimiento de un laudo arbitral parcial final al tener que decidir sobre la objeción de la empresa colombiana sobre la jurisdicción de los árbitros. La Corte reconoce el laudo arbitral al sostener la no afectación del orden público internacional colombiano.

15 Código de Comercio de Colombia, Artículo 1328: "Para todos los efectos, los contratos de agencia comercial que se ejecuten en el territorio nacional quedan sujetos a las leyes colombianas".

16 Zuleta Londoño (2010, p. 29) señala que "[...] existe una disposición en materia de agencia mercantil [Artículo 1328 del Código de Comercio] que, más que una regla de conflicto, parecería ser una especie de norma de policía, en el sentido de que su existencia impide el ejercicio de cualquier análisis de conflicto de leyes cuyo resultado señale como ley sustancial aplicable a un contrato de agencia mercantil ejecutado en Colombia, una ley sustancial diferente a la colombiana". 
diversos factores: la disponibilidad de las leyes, la fuente de la norma y su invocación a través de las partes (Clavel, 2012, pp. 59-66).

En cuanto a la situación en Colombia, la Corte Suprema de Justicia, en la citada sentencia del 24 de junio de 2016, sostiene que las normas sobre la agencia comercial contenidas en el Código de Comercio -incluido el Artículo 1328- fueron creadas "en un contexto histórico-económico en el que el legislador consideró necesario brindar protección al gremio de los agentes nacionales", dado que el agente colombiano era considerado parte débil de la relación contractual. Por ello, estas normas no permitían el ejercicio de la autonomía de la voluntad que condujera a la aplicación de una ley extrajera. Con el tiempo, sin embargo, los artículos que pretenden proteger este sector han pasado a ser considerados de carácter dispositivo. Esta postura se corresponde con el expreso reconocimiento de la libertad de escogencia de la ley aplicable en tanto manifestación de la autonomía de la voluntad que, como resalta la sentencia de la Corte Suprema recientemente indicada, se encuentra en la legislación colombiana en materia de arbitraje.

En efecto, el Artículo 101 de la Ley 1563 del 12 de julio de 2012, por medio de la cual se expide el estatuto de arbitraje nacional e internacional, es elocuente al establecer lo siguiente: "El tribunal arbitral decidirá de conformidad con las normas de derecho elegidas por las partes [...]". Anteriormente, el reconocimiento de la voluntad de las partes en esta materia se encontraba ya en el Artículo 2 de la anterior Ley 315 del 12 de septiembre de 1996 17 , incorporado luego en el Artículo 197 del Decreto 1818 del 7 de septiembre de 1998 relativo al estatuto de los mecanismos alternativos de solución de conflictos ${ }^{18}$.

En este sentido, también la jurisprudencia se ha pronunciado sobre la validez del pacto de ley aplicable a las relaciones privadas contractuales internacionales enmarcadas en el terreno del arbitraje internacional. Ya en 1997, el magistrado Eduardo Cifuentes Muñoz, en salvamento de

17 Ley 315 de 1996, Artículo 2: "El arbitraje internacional se regirá en todas sus partes de acuerdo con las normas de la presente ley, en particular por las disposiciones de los Tratados, Convenciones, Protocolo y demás actos de Derecho Internacional suscritos y ratificados por Colombia, los cuales priman sobre las reglas que sobre el particular se establecen en el Código de Procedimiento Civil. En todo caso, las partes son libres de determinar la norma sustancial aplicable conforme a la cual los árbitros habrán de resolver el litigio [...]".

18 Derogado posteriormente por la citada Ley 1563, del 12 de julio de 2012 (Artículo 118). 
voto de la Sentencia C-347/97 de la Corte Constitucional, en la que se decide sobre una demanda de inconstitucionalidad de algunos artículos de la entonces vigente ley de arbitraje ${ }^{19}$, manifestaba que las partes de un contrato mercantil internacional están facultadas para elegir, desde el momento de la celebración o al momento del surgimiento de la controversia, el derecho sustancial aplicable para resolver el asunto. Esta idea se encuentra plasmada en este salvamento de voto en los siguientes términos:

[...] tratándose de un asunto mercantil de carácter internacional, concurren, normalmente, dos o más ordenamientos jurídicos de Estados soberanos e independientes, con igual derecho a regular el asunto. En estas condiciones, no existe una regla de preferencia que ordene resolver el conflicto de leyes a favor del ordenamiento colombiano, pues no puede predicarse de este un "mejor derecho" de aquel que ostenta el ordenamiento extranjero, para imponerse a las partes al momento de resolver una eventual controversia.

En estos eventos, admitir el desplazamiento de las leyes nacionales, no entraña renuncia a la soberanía. Simplemente se acepta que, no existiendo reglas unívocas para solucionar los eventuales conflictos que pueden originarse a raíz de negocios de naturaleza internacional, las partes definan, en uso de su autonomía, pero dentro de un marco predeterminado por el derecho interno e internacional, las reglas que habrán de aplicarse para solucionar tales controversias. Se trata, en suma, de aceptar una excepción al principio de aplicación territorial de la ley, en los eventos en los cuales se verifican elementos internacionales respecto de las personas, los bienes, las relaciones o los efectos de contratos mercantiles que, por esa misma circunstancia, pueden ser regulados por dos o más ordenamientos jurídicos ${ }^{20}$.

En este mismo orden de ideas, recientemente la Corte Suprema consideraba que un laudo arbitral internacional era merecedor de reconocimiento puesto que "no se advierte que el laudo [...] desconozca los valores o principios básicos de la juridicidad nacional, pues [...] se

19 En esta sentencia se decide sobre la inconstitucionalidad de los artículos 1 y 4 de la Ley 315 del 12 de septiembre de 1996 sobre arbitraje internacional.

20 Corte Constitucional. Sentencia C-347/97. 23 de julio de 1997. M. P.: Jorge Arango Mejía. Salvamento de voto del magistrado Eduardo Cifuentes Muñoz. 
fundamentó en el respecto de la autonomía de la voluntad, que es precisamente el soporte nuclear de nuestro sistema contractual"21.

La jurisprudenca ha justificado, así, la validez del pacto de ley aplicable, abriendo la puerta para que las partes pueden acordar el derecho aplicable a un contrato con elementos de extranjería.

Ciertamente, en materia de arbitraje internacional, desde hace más de dos décadas existe en Colombia claridad en cuanto al reconocimiento legal de la posibilidad de escoger la ley aplicable al fondo del asunto. No obstante, cuando nos encontramos fuera de la materia de arbitraje internacional, y en particular al tratarse de contratos internacionales, el terreno bajo nuestros pies no ofrece tanta firmeza.

\section{Sinopsis de la situación en otros países: regulación expresa de la autonomía de las partes en materia contractual y en otras materias}

En las normas de derecho internacional privado latinoamericanas existe una tendencia que, sin ser absoluta ${ }^{22}$, se inclina hacia el reconocimiento expreso de la aplicación de la ley elegida por las partes en materia contractual. Esto se observa, por ejemplo, en la Ley de Derecho Internacional Privado de Venezuela, Artículos 29 y 3023, o en el Código Civil de Perú, Libro X, Artículo 209524. También el Código Civil y Comercial

21 Corte Suprema de Justicia. Sentencia SC9909-2017. Sala de Casación Civil. 12 de julio de 2017. M. P.: Aroldo Wilson Quiroz Monsalvo.

22 Como indica Basedow (2016, pp. 18 y ss.; 2017, pp. 109 y ss.), en Brasil y Uruguay tampoco se reconoce la autonomía de las partes para elegir la ley aplicable. Sobre la situación en Brasil donde, al igual que en Colombia, la legislación sobre arbitraje actúa como una "válvula" de escape a falta de un reconocimiento legal de la autonomía de la voluntad para elegir la ley aplicable a un contrato internacional, ver Brandão y Raizer (2013).

23 Ley de Derecho Internacional Privado de Venezuela, Artículo 29: "Las obligaciones convencionales se rigen por el Derecho indicado por las partes". Artículo 30: "A falta de indicación válida, las obligaciones convencionales se rigen por el Derecho con el cual se encuentran más directamente vinculadas. El tribunal tomará en cuenta todos los elementos objetivos y subjetivos que se desprendan del contrato para determinar ese Derecho. También tomará en cuenta los principios generales del Derecho Comercial Internacional aceptados por organismos internacionales".

${ }^{24}$ Código Civil de Perú, Artículo 2095: "Las obligaciones contractuales se rigen por la ley expresamente elegida por las partes $y$, en su defecto, por la ley del lugar de su cumplimiento. [...] 
de Argentina, en su Artículo 265125, acepta "expresa y decididamente, el principio de autonomía de la voluntad" en materia de contratos internacionales (Uzal, 2016, p. 310). Y la Convención Interamericana sobre el Derecho Aplicable a los Contratos Internacionales, adoptada en la Quinta Conferencia Especializada Interamericana sobre Derecho Internacional Privado de la Organización de Estados Americanos, celebrada en la Ciudad de México en 1994, de la cual no hace parte Colombia, expresamente establece en su Artículo $7^{26}$ que el contrato se rige por el derecho elegido por las partes.

En el sistema jurídico europeo, la autonomía de la voluntad de las partes, como factor de conexión, representa la regla general en materia de obligaciones contractuales, como se encuentra establecido en el Artículo 3, numeral 1, del Reglamento (CE) No 593/2008 del Parlamento Europeo y del Consejo del 17 de junio de 2008 sobre la ley aplicable a las obligaciones contractuales (Roma I) ${ }^{27}$. En el marco de esta normativa, la libertad de elección del derecho aplicable a la relación contractual internacional permite a las partes sustituir el conjunto de normas jurídicas aplicables al objeto de dicha relación, en virtud de las normas de conflicto, por las normas materiales de un ordenamiento jurídico ${ }^{28}$ que ellas mismas eligen.

Si el lugar del cumplimiento no está expresamente determinado o no resulta inequívocamente de la naturaleza de la obligación, se aplica la ley del lugar de celebración".

25 Código Civil y Comercial de Argentina, Artículo 2651: "Autonomía de la voluntad. Reglas. Los contratos se rigen por el derecho elegido por las partes en cuanto a su validez intrínseca, naturaleza, efectos, derechos y obligaciones. La elección debe ser expresa o resultar de manera cierta y evidente de los términos del contrato o de las circunstancias del caso. Dicha elección puede referirse a la totalidad o a partes del contrato. [...]". A continuación, el artículo establece algunas reglas específicas a las que debe sujetarse el ejercicio de la autonomía de la voluntad en este contexto.

26 Convención Interamericana sobre el Derecho Aplicable a los Contratos Internacionales, Artículo 7: "El contrato se rige por el derecho elegido por las partes. El acuerdo de las partes sobre esta elección debe ser expreso o, en caso de ausencia de acuerdo expreso, debe desprenderse en forma evidente de la conducta de las partes y de las cláusulas contractuales, consideradas en su conjunto. Dicha elección podrá referirse a la totalidad del contrato o a una parte del mismo.

La selección de un determinado foro por las partes no entraña necesariamente la elección del derecho aplicable".

27 Reglamento Roma I, Artículo 3.1: “El contrato se regirá por la ley elegida por las partes. Esta elección deberá manifestarse expresamente o resultar de manera inequívoca de los términos del contrato o de las circunstancias del caso. Por esta elección, las partes podrán designar la ley aplicable a la totalidad o solamente a una parte del contrato".

28 En Europa, con base en el Reglamento de Roma I, las partes solo pueden elegir normas 
Por otra parte, la posibilidad de elección de la ley aplicable puede estar presente, de igual forma, en normas conflictuales en materias distintas del ámbito contractual. En este sentido, en el derecho europeo, el Reglamento (UE) 2016/1103 del Consejo del 24 de junio de 2016, sobre regímenes económicos matrimoniales, permite, en su Artículo 22, que los cónyuges o contrayentes elijan o cambien la ley aplicable a su régimen económico matrimonial, escogiendo entre la ley del Estado en que conjuntamente, o de manera individual, tengan su residencia habitual al momento de celebrar la convención o del Estado de cuya nacionalidad sea(n) titular(es). En el mismo sentido, se halla el Reglamento (UE) 2016/1104 del Consejo del 24 de junio de 2016, respecto a los efectos patrimoniales en el régimen de vida común de uniones registradas. En este caso, los miembros de la unión pueden elegir, como ley aplicable, la ley del Estado donde uno o ambos tengan residencia habitual, la de su nacionalidad o la del Estado donde se registre la unión (Artículo 22).

El Artículo 5 del Reglamento (UE) 1259/2010 del Consejo del 20 de diciembre de 2010, referido a la ley aplicable al divorcio y a la separación judicial, faculta a los cónyuges para designar la ley aplicable del Estado donde tuvieran su residencia habitual, la del último lugar de su residencia habitual, la del Estado del que uno de los cónyuges sea nacional, en todos ellos al momento de celebrar el convenio de la elección y, finalmente, la ley del foro ${ }^{29}$.

En el caso de las sucesiones, el Artículo 21 del Reglamento (UE) 650/2012 del Parlamento Europeo y del Consejo, del 4 de julio de 2012, establece, como regla general, que es aplicable a la totalidad de la sucesión del causante la ley del Estado de la Unión Europea donde el ciudadano tuviera su residencia habitual al tiempo del fallecimiento. Sin embargo, el Artículo 22 permite a los ciudadanos escoger como ley aplicable la del Estado de cuya nacionalidad es titular y, en caso de que posea múltiples nacionalidades, puede elegir la ley de una de ellas.

materiales vigentes de un Estado miembro, es decir, hard law, mientras que la normativa interamericana permitiría incluso la elección de soft law (Oviedo Albán, 2012, pp. 126-127).

29 En este último caso, si la ley del foro lo permite, también podrán elegir los cónyuges "la ley aplicable ante el órgano jurisdiccional en el curso del procedimiento". 
En el marco de la Conferencia de La Haya de Derecho Internacional Privado, por su parte, se reconoce que los sujetos pueden escoger la ley aplicable a situaciones jurídicas internacionales en materias como sucesiones, protección de los adultos y matrimonio. El Convenio sobre la Ley Aplicable a los Regímenes Matrimoniales, de 1978, establece en su Artículo 3 que el régimen matrimonial se someterá a la ley interna designada por los cónyuges antes del matrimonio. A continuación, esta libertad de designación se limita a una de las siguientes leyes: la de un Estado del que uno de los cónyuges sea nacional en el momento de la designación, la del Estado en cuyo territorio uno de los cónyuges tenga su residencia habitual en el momento de la designación o la del primer Estado en cuyo territorio uno de los cónyuges establezca una nueva residencia habitual después del matrimonio. En lo que se refiere a los bienes inmuebles que ya posean o que adquieran con posterioridad, los cónyuges podrán optar por seguir la regla lex rei sitae y designar la ley del lugar en que tales inmuebles están situados.

También el Convenio sobre la Ley Aplicable a las Sucesiones por Causa de Muerte, de 1989, permite que cualquier persona designe la ley de un Estado determinado para que rija la totalidad de su sucesión (Artículo 5, numeral 1) o la ley de uno o más Estados para que se rija por ella la sucesión de algunos de sus bienes (Artículo 6). Rige, sin embargo, la condición basada en la nacionalidad o la residencia habitual del causante, pues dicha designación "solo surtirá efecto si, en el momento de la misma o en el del fallecimiento, dicha persona fuera nacional de ese Estado o tuviera su residencia habitual en el mismo" (Artículo 5.1). Por su parte, el Convenio sobre Protección Internacional de los Adultos, de 2000, contempla en su Artículo 15 que la existencia, alcance, modificación y extinción de los poderes de representación conferidos por un adulto, cuando dicho adulto no esté en condiciones de velar por sus intereses, se regirán por la ley del Estado de la residencia habitual del adulto en el momento del acuerdo o del acto unilateral, y establece como excepción que se haya designado expresamente por escrito la ley de alguno de los Estados siguientes: un Estado del que el adulto posea la nacionalidad, el Estado de la anterior residencia habitual del adulto o un Estado en el que se encuentren situados bienes del adulto, con respecto a dichos bienes. 
En todas estas normas, al igual que ocurre con las normas adoptadas en la Unión Europea, mencionadas más arriba, la posibilidad de elección que se ofrece a los sujetos involucrados en cada una de las respectivas situaciones jurídicas es manifestación palmaria de la autonomía de la voluntad.

Aunque Colombia no hace parte de los tratados de la Conferencia de La Haya que se han mencionado, así como tampoco de la referida Convención Interamericana sobre el Derecho Aplicable a los Contratos Internacionales $-\mathrm{y}$, naturalmente, ni las normas de la Unión Europea ni las de otros ordenamientos jurídicos nacionales son aplicables en su territorio-, las normas incluidas en tales instrumentos no son del todo irrelevantes para el ordenamiento jurídico colombiano. Estas pueden considerarse al hacer parte del soft law internacional y su aplicabilidad podría fundamentarse en el Artículo 7 del Código de Comercio ${ }^{30}$, así como en el Artículo 101 de la Ley 1563 del 2012, que otorga a las partes la facultad de elegir el derecho de conformidad con el cual deberá decidir el tribunal arbitral, con lo cual la norma no se estaría limitando al derecho positivo de un Estado en particular (Zapata, 2016, p. 207).

En cualquier caso, la breve exposición que se ha realizado sobre la situación normativa en otros países sirve para reafirmar la necesidad de que el Estado colombiano revise su legislación en esta materia. Así mismo, a través de dicha exposición, se han mostrado algunas formas posibles de regular expresamente y con claridad la autonomía de las partes en materia de contratos internacionales, así como también su actual aplicación más allá del campo contractual.

\section{Consideraciones para una posible regulación en Colombia}

\section{Flexibilización de las normas de conflicto}

Al defenderse el reconocimiento legal de la voluntad de las partes como factor de conexión, se suele afirmar que este contribuye a la seguridad

30 Código de Comercio de Colombia, Artículo 7: "Los tratados o convenciones internacionales de comercio no ratificados por Colombia, la costumbre mercantil internacional que reúna las condiciones del Artículo $3^{\circ}$, así como los principios generales del derecho comercial, podrán aplicarse a las cuestiones mercantiles que no puedan resolverse conforme a las reglas precedentes". 
jurídica, puesto que los sujetos pueden establecer de manera fija y previsible el derecho que ha de aplicarse (Junker, 2017, p. 63; Mantilla Rey, 1982, p. 18; Bernasconi, 2016, p. 8). Sin embargo, la seguridad jurídica como fundamento del reconocimiento de la autonomía de las partes no está fuera de toda discusión. En efecto, por lo general se considera que, en materia de derecho internacional privado, la seguridad jurídica es un atributo de las normas codificadas que establecen cuál será la ley aplicable. No obstante, desde este punto de vista, podría decirse que poco contribuiría a la seguridad jurídica una norma que no establezca directamente cuál es la ley aplicable, sino que, por el contrario, confiriera plena libertad a las partes para escoger la ley a aplicar a la situación, otorgándoles una especie de cheque en blanco. Ello justificaría inquietudes, como las referidas a las desigualdades que pueden subyacer entre las partes o a su falta de conocimiento suficiente respecto de los diversos órdenes jurídicos.

Por otra parte, resulta claro que la existencia de normas de conflicto de leyes unilaterales y rígidas no facilita la realización de negocios transfronterizos ni la solución de una gran diversidad de situaciones jurídicas privadas internacionales. Tal es el caso, por ejemplo, de las normas de conflicto sobre contratos incluidas en los mencionados artículos del Código Civil (Artículo 20, párrafos segundo y tercero) y del Código de Comercio (artículos 869 y 1328). La unilateralidad de estas normas se pone de manifiesto en el hecho de que conducen a la aplicación exclusiva del ordenamiento jurídico colombiano, que es expresión, así mismo, de territorialismo. Y su rigidez se refleja, ante todo, en la inclusión de un único factor de conexión, además de no incorporar ninguna otra forma de flexibilización, que se indicarán más adelante.

Tomando en cuenta lo anterior, expondremos a continuación algunas consideraciones que pueden ser relevantes al definir una posible regulación sobre la materia en Colombia. Con ello buscamos contribuir a la tarea que ha de emprenderse para establecer normas codificadas que, al regular expresa y claramente la libertad de las partes para la elección del derecho aplicable, ofrezcan, a la vez, una mayor seguridad jurídica en este campo.

En primer lugar, nos basaremos en la idea de flexibilización como ha sido planteada por Symeonides $(2011,2014)$ y, en esta medida, distinguimos entre cuatro formas a través de las cuales las normas de conflicto 
pueden flexibilizarse y han sido, de hecho, flexibilizadas en diferentes legislaciones del mundo ${ }^{31}$.

En primer lugar, se encuentra el uso de factores de conexión alternativos que consisten en la incorporación dentro de la norma de conflicto de diferentes circunstancias fácticas para determinar la ley aplicable. El resultado es una norma de conflicto con varios factores de conexión, cada uno de los cuales podrá aplicarse a la situación de hecho de la norma de forma alternativa, es decir, podrá escogerse entre la aplicación de uno u otro. Esta forma de flexibilización la hemos visto en normativas en materias especiales, como familia o sucesiones. En ellas, si bien se contempla la libertad de los sujetos para escoger la ley que regirá la situación jurídica, esta se encuentra limitada por la posibilidad de escoger entre determinados factores de conexión que se establecen de manera alternativa. A este respecto se pueden observar, por mencionar solo dos ejemplos, el Artículo 3 del Convenio de La Haya sobre la Ley Aplicable a los Regímenes Matrimoniales, de 1978; y el Artículo 22 del Reglamento (UE) 650/2012 del 4 de julio de 2012, ambos citados anteriormente. De manera más específica, Basedow (2017) habla del uso de factores de conexión "en cascada" o "en escalera", caso en el que "el factor de conexión empleado en el escalón posterior solo entra en juego cuando no se den los hechos requeridos por el escalón anterior" (Basedow, 2017, p. 58). Ejemplos de esto último se encuentran en el Artículo 8 del Reglamento (UE) 1259/2010 del 20 de diciembre de 2010, referido a la ley aplicable al divorcio y a la separación judicial; y en el Artículo 14, párrafos 1 a 3, de la Ley Introductoria al Código Civil de Alemania.

En segundo lugar, encontramos otra forma de flexibilización que consiste en el uso de los factores de conexión que Symeonides denomina blandos, lo que se traduce en la incorporación del vínculo más estrecho como circunstancia fáctica para determinar la ley aplicable, y que también se conoce como "principio de proximidad" (Organización de Estados Americanos, 2016). Ejemplos de ello se encuentran en el Artículo 4, numeral 3, del Reglamento (CE) 593/2008 del 17 de junio de

31 Por razones de espacio, no consideramos en toda su extensión y detalle la clasificación y ejemplificación de formas de flexibilización que hace Symeonides $(2011 ; 2014)$. 
2008 (Roma I) ${ }^{32}$. De igual forma, pero con un alcance material amplio, el Artículo 2595 del Código Civil y Comercial de Argentina ${ }^{33}$ establece que el sistema jurídico que se aplicará a una relación jurídica, a la que sean aplicables varios sistemas jurídicos, será el que presente los vínculos más estrechos con dicha relación.

Las otras dos formas de flexibilización a las que se refiere Symeonides consisten, por una parte, en el uso de cláusulas de escape y, por otra, en el establecimiento de lo que él llama aproximaciones. Las cláusulas de escape dan a la autoridad competente la facultad de ajustar, o dejar de aplicar, una norma de conflicto cuando las circunstancias de la situación particular así lo exijan. El autor indica, como ejemplo de una norma que incluye una cláusula de escape, el Artículo 15 de la Ley de Derecho Internacional Privado de Suiza ${ }^{34}$. Por su parte, las aproximaciones, a diferencia de las normas de conflicto en sentido estricto, no designan el ordenamiento jurídico aplicable de forma directa sino que lo hacen a través de la referencia a parámetros generales, tales como principios, políticas $\mathrm{u}$ otros factores, a través de los que los jueces pueden, a posteriori y ad hoc, escoger el derecho aplicable, con base en la consideración de las circunstancias del caso, de lo que es un ejemplo, en Estados Unidos, la Sección 6 del Restatement (Second) of Conflict of Law ${ }^{35}$ (Symeonides, 2011).

32 Reglamento Roma I, Artículo 4, numeral 3: "Si del conjunto de circunstancias se desprende claramente que el contrato presenta vínculos manifiestamente más estrechos con otro país distinto del indicado en los apartados 1 o 2, se aplicará la ley de este otro país".

33 Código Civil y Comercial de la Nación, Argentina, Artículo 2595, literal b: "Cuando un derecho extranjero resulta aplicable [...] si existen varios sistemas jurídicos covigentes con competencia territorial o personal, o se suceden diferentes ordenamientos legales, el derecho aplicable se determina por las reglas en vigor dentro del Estado al que ese derecho pertenece $y$, en defecto de tales reglas, por el sistema jurídico en disputa que presente los vínculos más estrechos con la relación jurídica de que se trate".

34 Ley de Derecho Internacional Privado de Suiza, Artículo 15: "1. Como excepción, cualquier ley referida por esta Ley no es aplicable si, considerando todas las circunstancias, es evidente que el caso tiene una conexión muy débil con tal ley y que el caso tiene una conexión mucho más estrecha con otra ley. 2. Esta disposición no se aplica cuando se ha elegido una ley". (Traducción libre). Ver Considerando 20 del Reglamento (CE) No. 593/2008 del 17 de junio de 2008 (Roma I).

35 Restatement (Second) of Conflict of Law, Sección 6 (cit. por Symeonides, 2011): "Los factores relevantes para la elección del derecho aplicable incluyen (a) las necesidades de los sistemas interestatales e internacionales, (b) las políticas relevantes del foro, (c) las políticas relevantes de otros Estados interesados y los intereses relativos de esos Estados en la determinación de la cuestión particular, (d) la protección de las expectativas justificadas, (e) las políticas básicas que 
Si se parte de la existencia de esas cuatro formas de flexibilización, no podría, entonces, afirmarse que las normas que reconocen la autonomía de las partes para elegir la ley aplicable son, en sí mismas y necesariamente, normas de conflicto flexibles. Sin embargo, estas normas pueden incluir elementos incorporados en las formas de flexibilización que han sido identificadas. De esta forma, se pueden formular normas que, por una parte, se adecúen a las exigencias de las realidades que emergen de hechos y negocios jurídicos contemporáneos y, por otra parte, delimiten el alcance de la autonomía de las partes en la elección del derecho aplicable a las situaciones jurídicas en las que participan.

Así, por ejemplo, las dos primeras formas, es decir, la inclusión de factores de conexión alternativos y la consideración del vínculo más estrecho, desempeñarían aquí un papel particular. Por una parte, los factores de conexión alternativos pueden configurar una forma flexible de delimitar la libertad de las partes en la escogencia de la ley aplicable. Por otra, el uso del vínculo más estrecho como factor de conexión puede tener lugar si las partes no han elegido el derecho aplicable o si la elección que hubieren hecho resultare ineficaz, como ocurre en el Artículo 9 de la Convención Interamericana sobre el Derecho Aplicable a los Contratos Internacionales ${ }^{36}$. En este caso, con el fin de determinar la existencia de esos vínculos más estrechos, el tribunal tomará en cuenta todos los elementos objetivos y subjetivos que puedan desprenderse del contrato y los principios generales del derecho comercial internacional reconocidos por organizaciones internacionales.

subyacen a un campo de derecho particular, (f) certeza, previsibilidad y uniformidad del resultado, y (g) facilidad en la determinación y aplicación de la ley a ser aplicada". (Traducción libre).

36 Convención Interamericana sobre el Derecho Aplicable a los Contratos Internacionales, Artículo 9: "Si las partes no hubieran elegido el derecho aplicable, o si su elección resultara ineficaz, el contrato se regirá por el derecho del Estado con el cual tenga los vínculos más estrechos.

El tribunal tomará en cuenta todos los elementos objetivos y subjetivos que se desprendan del contrato para determinar el derecho del Estado con el cual tiene vínculos más estrechos. También tomará en cuenta los principios generales del derecho comercial internacional aceptados por organismos internacionales.

No obstante, si una parte del contrato fuera separable del resto del contrato y tuviese una conexión más estrecha con otro Estado, podrá aplicarse, a título excepcional, la ley de este otro Estado a esta parte del contrato". 


\section{Internacionalidad de la situación y desigualdad entre las partes}

Como se ha mencionado, existen dos circunstancias que han de ser atendidas especialmente al considerar la posibilidad de que los individuos envueltos en una situación jurídica privada internacional puedan elegir la ley aplicable a dicha situación. Nos referimos, por una parte, al hecho de que es común que entre los ciudadanos no exista una conciencia y un conocimiento cierto acerca de la internacionalidad de la situación, es decir, acerca de la diversidad legislativa que existe entre los diferentes países y las consecuencias que pueden derivar de aplicar un ordenamiento jurídico u otro (Jayme, 2012, p. 35). Esto, que tendría que considerarse un presupuesto necesario para que las partes puedan hacer una elección informada y libre de la legislación que regirá la situación en la que se encuentran envueltos, no es un asunto de fácil solución. Baste, por ahora, anotar la necesidad de considerarlo en el caso de una revisión normativa sobre el tema.

Por otra parte, un asunto de suma importancia que ha de tenerse en cuenta es la debilidad o vulnerabilidad en la que se puede encontrar una de las partes frente a la otra (Basedow, 2017, pp. 127 y ss.; Jayme, 2012, p. 35). Si bien lo dicho cobra particular relevancia en ciertas materias, como el derecho de familia - contexto en el que lo resalta Jayme (2012)-, es igualmente significativo en materia contractual. En este sentido, al comentar los Principios de La Haya sobre la Elección del Derecho Aplicable en Materia de Contratos Comerciales Internacionales, Symeonides, que hacía parte del grupo de trabajo que preparó dichos principios, advertía:

[...] los Principios adoptan una postura decididamente liberal hacia la autonomía de las partes, ejemplificada, entre otras cosas, por un fuerte respaldo de las normas no estatales. Tal liberalidad sería inobjetable, de hecho, apropiada, si la "comercialidad" de un contrato por sí sola excluyera la disparidad de poder de negociación que caracteriza los contratos de consumo y de empleo. El hecho de que, como lo ilustran los contratos de franquicia, este no es siempre el caso, hace aún más necesario el despliegue de otros mecanismos de vigilancia de la autonomía de las partes (2013, p. 873). 
Esta preocupación se ha traducido de manera concreta, por ejemplo, en el Artículo 2651 del Código Civil y Comercial de Argentina, que reconoce el principio de autonomía de las partes para elegir la ley aplicable a los contratos internacionales y establece, expresamente, en su parte final: "Este artículo no se aplica a los contratos de consumo". Como resalta Basedow (2016, p. 23), las restricciones en la elección de la ley aplicable son comunes, en especial, al tratarse de ciertos tipos de contratos. En el marco del Reglamento (CE) 593/2008 del 17 de junio de 2008 (Roma I), esto ocurre, por ejemplo, en relación con los contratos de consumo (Artículo 6), de seguro (Artículo 7) y de trabajo (Artículo 8) ${ }^{37}$.

En este orden de ideas, la utilización de elementos flexibilizadores, como los que han sido anotados más arriba, puede contribuir a paliar los riesgos que lleguen a derivarse de una autonomía de las partes carente de límites o de cualquier tipo de vigilancia.

En el contexto colombiano se puede encontrar, fuera del ámbito contractual, un ejemplo elocuente de una norma de conflicto flexible en la que se ha tomado en cuenta la debilidad o vulnerabilidad en la que se puede encontrar una de las partes. Se trata del Artículo 6 de la Convención Interamericana sobre Obligaciones Alimentarias (Ley aprobatoria 449 de 1998). En dicha norma se incorporan dos factores de conexión alternativos, dejando la elección entre uno u otro en manos de la autoridad competente, que tendrá como criterio la búsqueda del mayor beneficio para el interés del acreedor. En efecto, según dicho artículo, a las obligaciones alimentarias les será aplicable:

[...] aquel de los siguientes órdenes jurídicos que, a juicio de la autoridad competente, resultare más favorable al interés del acreedor:

a. El ordenamiento jurídico del Estado del domicilio o de la residencia habitual del acreedor;

b. El ordenamiento jurídico del Estado del domicilio o de la residencia habitual del deudor. 
Este ejemplo muestra que la flexibilización de las normas de conflicto no es del todo extraña en el ordenamiento jurídico colombiano, si bien la norma mencionada es de origen internacional ${ }^{38}$ y su existencia en el marco de un tratado limita su alcance a las situaciones jurídicas que tienen conexión con Estados en los cuales el mismo sea vinculante.

\section{Conclusiones}

La necesidad que existe en Colombia de una regulación expresa y clara, en materia de elección de ley aplicable a las relaciones jurídicas privadas internacionales, es insoslayable. Como se observó, los artículos que al respecto se encuentran en el Código Civil y en el Código de Comercio son anacrónicos e insuficientes frente a los diversas posibles situaciones con elementos de extranjería. Interpretaciones doctrinarias y desarrollos en el campo jurisprudencial no ofrecen una solución plenamente satisfactoria mientras no existan, en el ámbito nacional, normas codificadas que regulen, expresa y claramente, la libertad de las partes para la elección del derecho aplicable en materia de contratación internacional -lo que podría ser evaluado también en otras materias como familia y sucesiones-, como sí existe en materia de arbitraje.

La formulación de una regulación en esta materia supone el desarrollo de una labor que habrá de estar basada en un estudio profundo del contenido y del alcance de cada norma en concreto. En tanto se tratará, en un grado importante, de establecer normas de conflicto de leyes, las consideraciones en torno a las herramientas que brinda la flexibilización en la labor codificadora, incluidas en este artículo, son particularmente relevantes.

38 Puede hacerse una breve anotación en relación con la norma de conflicto incluida en el Artículo 83 de la Ley 1676 de 2013, por la cual se promueve el acceso al crédito y se dictan normas sobre garantías mobiliarias. Una lectura inicial de dicho artículo podría conducir a afirmar que el mismo contiene una norma de conflicto flexible en el sentido que se ha expuesto, puesto que en él se encuentran varios factores de conexión. Sin embargo, ha de tenerse en cuenta que en dicho artículo cada uno de los factores de conexión está asociado a diferentes supuestos de hecho. Ello conduce a que no pueda afirmarse que existe, propiamente, una alternación entre los diferentes factores de conexión ya que no se puede optar entre la aplicación de un factor de conexión u otro. 
Así mismo, será menester atender a las consideraciones anotadas en relación con la necesidad de tratar de asegurar que la elección de la legislación que regirá la situación sea una elección informada, así como la de asegurarse la consideración de la posible debilidad o vulnerabilidad en la que se puede encontrar una de las partes frente a la otra.

En cualquier caso, se requerirá de un estudio comparado profundo de las normativas nacionales e interamericanas. Así mismo, habrán de tenerse en cuenta discusiones que han tenido lugar en los planos internacional y regional para dar lugar a los instrumentos de soft law que han sido adoptados por organizaciones internacionales. En tal sentido, son de mencionar la Conferencia de La Haya de Derecho Internacional Privado $^{39}$, el Instituto Internacional para la Unificación del Derecho Privado (Unidroit) ${ }^{40}$ y otras organizaciones, como la Commission on European Contract $\operatorname{Law}^{41}$ y la Asociación Americana de Derecho Internacional Privado (ASADIP ${ }^{42}$ que han elaborado sus respectivos instrumentos también con el fin de que sean considerados disposiciones modelo en procesos legislativos a nivel nacional.

\section{Referencias}

Álvarez Londoño, L. y Galán Barrera, D. (2001). Derecho internacional privado (parte general). Bogotá: Pontificia Universidad Javeriana.

Asociación Americana de Derecho Internacional Privado. (2018). Principios latinoamericanos de derecho de los contratos. Recuperado de http://pldc.uexternado.edu.co/PLDC-3xternado/wp-content/uploads/2018/01/PLDC2017-Versión-español.pdf (abril, 2018).

39 Principios sobre la Elección del Derecho Aplicable en Materia de Contratos Comerciales Internacionales (2015).

40 Principios Unidroit sobre los Contratos Comerciales Internacionales (1994-2016).

41 Principles of European Contract Law (PECL).

42 Recientemente han sido adoptados en el seno de la ASADIP los Principios Latinoamericanos de Derecho de los Contratos (2018). Es muy valiosa la publicación que recoge las discusiones preparatorias, dirigida por Fernández Arroyo y Moreno Rodríguez (2016). Ver también: Madrid (2018) y Morales Moreno (2014). 
Basedow, J. (2016). Theory of choice of law and party autonomy. En D. Fernández Arroyo y J. A. Moreno Rodríguez (eds.), Contratos internacionales (pp. 17-47). Buenos Aires: ASADIP/OEA.

Basedow, J. (2017). El derecho de las sociedades abiertas. Ordenación privada y regulación pública en el conflicto de leyes. Bogotá: Legis.

Bernasconi, C. (2016). Principios sobre la elección del derecho aplicable en materia de contratos comerciales internacionales. Preámbulo. La Haya: Oficina Permanente de la Conferencia de La Haya de Derecho Internacional Privado. Recuperado de https://assets.hcch.net/docs/21356f80-f371-4769-af20-a5e70646554b. pdf (abril, 2018).

Brandão, A. y Raizer, V. (2013). Un enfoque crítico del sistema brasileño de derecho internacional privado y los retos de la armonización: los nuevos Principios de La Haya sobre la elección del derecho aplicable en materia de contratos internacionales. Anuario Español de Derecho internacional privado, XIII, 665-679.

Caicedo Castilla, J. (1967). Derecho internacional privado. Bogotá: Temis.

Calderón Marenco, E. (2017). Aplicación normativa de la compraventa internacional de mercaderías. Revista de Derecho, (22), 37-60.

Calvo Caravaca, A. y Carrascosa González, J. (2015). Derecho internacional privado. Volumen I. Madrid: Comares Editorial.

Clavel, S. (2012). Droit international privé. París: Dalloz.

Cock Arango, A. (1952). Tratado de derecho internacional privado. Bogotá: Universidad Nacional de Colombia.

Conferencia de La Haya. (2015). Principios sobre la elección del derecho aplicable en materia de contratos comerciales internacionales. Recuperado de https://assets. hcch.net/docs/21356f80-f371-4769-af20-a5e70646554b.pdf (abril, 2018).

Consejo de Estado. (2015). Ref. 11001-03-26-000-2015-00103-00 (54549).

Sala de lo Contencioso Administrativo. Sección Tercera. 4 de septiembre de 2015. C. P.: Jaime Orlando Santofimio Gamboa.

Corte Constitucional de Colombia. (1997). Sentencia C-347/97. 23 de julio de 1997. M. P.: Jorge Arango Mejía.

Corte Constitucional de Colombia. (2000). Sentencia C-529/00. 10 de mayo de 2000. M. P.: Antonio Barrera Carbonell.

Corte Suprema de Justicia de Colombia. (2002). Exp. T-11001220300020020109-01. Sala de Casación Civil. 18 de abril de 2002. M. P.: José Fernando Ramírez Gómez. 
Corte Suprema de Justicia de Colombia. (2012). Exp. 11001-3103-040-200600537-01. Sala de Casación Civil. 21 de febrero de 2012. M. P.: William Namén Vargas.

Corte Suprema de Justicia de Colombia. (2016). Sentencia SC8453-2016. Sala de Casación Civil. 24 de junio de 2016. M. P.: Ariel Salazar Ramírez.

Corte Suprema de Justicia de Colombia. (2017). Sentencia SC9909-2017. Sala de Casación Civil. 12 de julio de 2017. M. P.: Aroldo Wilson Quiroz Monsalvo. Corte Suprema de Justicia de Colombia. (2017). Exp. 11001-3103-040-200600537-01. Sala de Casación Civil. 21 de febrero de 2017. M. P.: William Namén Vargas.

García Matamoros, L. y Aljure Salame, A. (2016). Teoría general del derecho internacional privado. Bogotá: Universidad del Rosario/Legis.

Guerra Iñiguez, D. (1997). Derecho internacional privado. Caracas: Distribuidora Kelran.

Fernández Arroyo, D. y Moreno Rodríguez, J. (2016). Contratos internacionales. Buenos Aires: ASADIP/OEA.

Jayme, E. (2012). Zugehörigkeit und kulturelle Identität. Die Sicht des internationalen Privatrechts. Reden am Lichtenberg-Kolleg. Gotinga: Wallstein Verlag.

Junker, A. (2017). Internationales Privatrecht. Múnich: C. H. Beck.

Kegel, G. (1982). Derecho internacional privado. Bogotá: Ediciones Rosaristas.

Larenz, K. (1956). Base del negocio jurídico y cumplimiento del contrato. Madrid: Editorial Revista de Derecho Privado.

Leible, S. (2011). La importancia de la autonomía conflictual para el futuro del derecho de los contratos internacionales. Cuadernos de Derecho Transnacional, 3(1), 214-233.

Madrid, C. (2016). Los contrados no bilateralmente negociados: más allá del consumidor. En D. Fernández Arroyo y J. A. Moreno Rodríguez (eds.), Contratos internacionales, pp. 437-456. Buenos Aires: ASADIP/OEA.

Madrid, C. (2018). Principios latinoamericanos de derecho de los contratos. Cartas Blogatorias [blog]. Recuperado de https://cartasblogatorias.com/2018/04/10/ principios-latinoamericanos-de-derecho-de-los-contratos/ (abril, 2018).

Mantilla Rey, R. (1982). Apuntes de derecho internacional privado. Bogotá: Temis.

Marín Fuentes, J. (2014). Derecho internacional privado. Medellín: Universidad de Medellín.

Monroy Cabra, M. (2016). Tratado de derecho internacional privado. Bogotá: Temis. Morales Moreno, A. (2014). Los principios latinoamericanos de derecho de los contratos. Un debate abierto sobre las grandes cuestiones jurídicas de la contratación. $A D C, L X V I I$, fasc. I, 227-254. 
Orejudo Prieto, P. (2013). El derecho internacional privado colombiano ante la Ley Modelo OHADAC de DIPr. Anuario Español de Derecho internacional privado, XIII, 681-697.

Organización de Estados Americanos. (2016). La Convención Interamericana sobre derecho aplicable a contratos internacionales y el avance de sus principios en las Américas. Documento OEA/SG DDI/doc. 3/16, del 15 marzo de 2016.

Oviedo Albán, J. (2012). La ley aplicable a los contratos internacionales. Revista Colombiana de Derecho Internacional, (21), 117-157.

Oviedo Albán, J. (2013). Los principios UNIDROIT como reglas aplicables al contrato internacional. Cuadernos de la Maestría en Derecho, (3), 7-22.

Rodríguez, M. (2011). El principio de la autonomía de la voluntad y el derecho internacional privado: asimetrías en su reconocimiento y necesidad de armonización legislativa en el Mercosur. Revista Científica de Publicaciones de las Ciencias Empresariales, Sociales y de la Salud, 15(1), 112-143.

Ruiz Díaz, R. (2013). Friedrich Karl Von Savigny e o direito internacional privado: vigência de sua doutrina. Revista da Secretaria do Tribunal Permanente de Revisão, 1(2), 247-270.

Samtleben, J. (1983). Derecho internacional privado en América Latina. Teoría y práctica del Código Bustamante. Volumen I. Buenos Aires: DePalma.

Schurig, K. (2014). Das Fundament trägt noch. En H.-P. Mansel (ed.), Internationales Privatrecht im 20. Jahrhundert, pp. 5-25. Tubinga: Mohr Siebeck.

Soto Coaguila, C. (2005). Transformación del derecho de contratos. Lima: Editora Jurídica Grijley.

Symeonides, S. (2011). Codification and flexibility in private international law. Willamette University-College of Law. Retrieved from http://papers.ssrn.com/ sol3/papers.cfm?abstract_id=1945924 (septiembre, 2017).

Symeonides, S. (2013). The Hague Principles on choice of law for international contracts: Some preliminary comments. The American Journal of Comparative Law, 61(4), 873-899.

Symeonides, S. (2014). Codifying choice of law around the world. An international comparative analysis. Oxford: Oxford University Press.

Symeonides, S. (2016). Choice of law. The Oxford commentaries on American law. Nueva York: Oxford University Press.

Tribunal Superior de Bogotá. Sentencia 242001429 01. Sala Civil. 30 de abril de 2002.

Unidroit. (2016). Principios de los contratos internacionales mercantiles. Recuperado de https://www.unidroit.org/instruments/commercial-contracts/unidroitprinciples-2016 (abril, 2018). 
Uzal, M. (2016). Los contratos internacionales en Argentina. En D. Fernández Arroyo y J. A. Moreno Rodríguez (eds.), Contratos internacionales (pp. 307333). Buenos Aires: ASADIP/OEA.

Zapata, A. (2016). La ley aplicable al contrato internacional. En L. García Matamoros y A. Aljure Salame (eds.), Teoría general del derecho internacional privado, pp. 189-217. Bogotá: Universidad del Rosario/Legis.

Zuleta Londoño, A. (2010). Las cláusulas de selección de foro y selección de ley en la contratación internacional: una visión desde el derecho internacional privado colombiano. Revista de Derecho Privado, (44), 1-35. 